\title{
Forced migration and health - diarrhoea among adult Zimbabwean immigrants in Limpopo
}

\author{
Thando P Gwetu, Annette A M Gerritsen, Henry A Akinsola
}

To the Editor: The political and economic decline in Zimbabwe has forced many Zimbabweans to migrate to neighbouring countries and abroad. ${ }^{1}$ A large number of Zimbabwean migrants live in poverty in the border region. The high demand for shelter forces some people to create and occupy very basic dwellings ${ }^{2}$ and cook food in tin cans over fires. Many live in cardboard and plastic shelters, some in the back yards of overcrowded homes where they have to pay rent. Others sleep under trees next to roads or on open fields on farms, at railway stations or on the street. ${ }^{3}$

Recently many people fled to South Africa from the deadly cholera epidemic in Zimbabwe, which killed more than 2000 people in 4 months. ${ }^{4}$ Cholera outbreaks have been experienced in Zimbabwe since October 2008. People who are infected but have no symptoms can carry the disease and cause it to spread. ${ }^{5}$ Initially most of the cholera cases in South Africa were Zimbabweans seeking health care. $^{6}$

We show that the conditions under which informal residents live put them at high risk of diarrhoea.

\section{Methods}

This cross-sectional study assessed Zimbabwean immigrants aged 18 years and over in a convenience sample from five sampling sites. It was conducted over 2 weeks in March 2010 in Louis Trichardt, $115 \mathrm{~km}$ from the Zimbabwe border. A questionnaire covering socio-demographic features, living conditions, health risk factors (water quality, sanitation and hygiene) and diarrhoea morbidity was administered to 110 participants forced to migrate due to political concerns, conflict, poverty and lack of jobs. Diarrhoea was defined as 3 or more loose stools in a 24 -hour period.

\section{Results}

Males predominated $(89 ; 80.9 \%)$. The median age for males was 23 years (95\% confidence interval (CI) 20 - 27 years) and that for females 23 years (95\% CI 20 - 29 years). With regard to their legal status in South Africa, 83 (75.5\%) had temporary asylum permits from the South African Department of Home Affairs. Secondary school was the highest level of education for 84 subjects (76.4\%). The median number of people living in the participants' residential premises was 60 (95\% CI 18 - 153) ('residential premises' refers to an inhabited property within a single yard, consisting of either private housing or a public shelter).

The median duration of the subjects' current stay in South Africa was 2 months (95\% CI 0 - 12 months). Individual monthly

Thando P Gwetu, MB ChB, MPH

Department of Public Health, University of Venda, Thohoyandou, Limpopo

Annette A M Gerritsen, $\mathrm{PhD}$ (Epidemiology)

Epi Result, Louis Trichardt, and Department of Public Health, University of the

Witwatersrand, Johannesburg

Henry A Akinsola, $\mathrm{PhD}$

Department of Public Health, University of Venda expenditure was low, being less than R300 in 58 cases (52.7\%). Medians were used instead of means because the data were skewed.

The prevalence of diarrhoea in this study was $24.5 \%$. The mean number of diarrhoea episodes was 0.38 per person in 2 weeks. For participants with diarrhoea, the most recent episode had lasted 2 days ( 9 cases, $33.3 \%), 3$ days $(8,29.6 \%), 1$ day $(6,22.2 \%)$, 4 days $(2,7.4 \%)$ and 7 days $(2,7.4 \%)$. The relationships between diarrhoea and labour force status (Fisher's exact test $p=0.023$ ), living conditions (Fisher's exact test $p=0.050$ ) and monthly expenditure (Fisher's exact test $p=0.037$ ) were statistically significant. Other variables evaluated and their relationship with diarrhoea are set out in Table I.

Table I. Variables evaluated and their relationship with diarrhoea

\begin{tabular}{|c|c|c|}
\hline Variable & Diarrhoea & $p$-value \\
\hline \multicolumn{3}{|l|}{ Gender } \\
\hline Male & $20 / 89(22.5 \%)$ & 0.298 \\
\hline Female & $7 / 21(33.3 \%)$ & \\
\hline \multicolumn{3}{|l|}{ Education } \\
\hline Illiterate & $1 / 2(50.0 \%)$ & 0.223 \\
\hline Primary & $3 / 13(23.1 \%)$ & \\
\hline Secondary & $18 / 84(21.4 \%)$ & \\
\hline Tertiary & $5 / 11(45.5 \%)$ & \\
\hline \multicolumn{3}{|l|}{ Residence status } \\
\hline Asylum & $22 / 83(26.5 \%)$ & 0.804 \\
\hline No permit & $3 / 17(17.6 \%)$ & \\
\hline Temporary visa & $2 / 10(20.0 \%)$ & \\
\hline \multicolumn{3}{|l|}{ Labour force status } \\
\hline Unemployed & $9 / 36(25.0 \%)$ & 0.023 \\
\hline Piece-jobs & $8 / 51(15.7 \%)$ & \\
\hline Job with contract & $8 / 14(57.1 \%)$ & \\
\hline Job no contract & $2 / 9(22.2 \%)$ & \\
\hline \multicolumn{3}{|c|}{ Water supply at home } \\
\hline Private tap & $21 / 81(25.9 \%)$ & 0.476 \\
\hline Public tap & $2 / 18(11.1 \%)$ & \\
\hline Well & $3 / 9(33.3 \%)$ & \\
\hline Borehole & $1 / 2(50.0 \%)$ & \\
\hline \multicolumn{3}{|l|}{ Waste water disposal } \\
\hline Piped drain & $19 / 75(25.3 \%)$ & 9.613 \\
\hline Yard & $8 / 29(27.6 \%)$ & \\
\hline River & $0 / 1(0 \%)$ & \\
\hline Toilet & $0 / 5(0 \%)$ & \\
\hline \multicolumn{3}{|l|}{$\begin{array}{l}\text { Hand washing with } \\
\text { soap }\end{array}$} \\
\hline Yes & $8 / 43(18.6 \%)$ & 0.246 \\
\hline No & $19 / 67(28.4 \%)$ & \\
\hline
\end{tabular}


Table I. Variables evaluated and their relationship with diarrhoea (continued)

\begin{tabular}{|c|c|c|}
\hline Variable & Diarrhoea & $p$-value \\
\hline \multicolumn{3}{|l|}{ Food storage } \\
\hline Yes & $16 / 35(45.7 \%)$ & 0.252 \\
\hline No & $11 / 75(14.7 \%)$ & \\
\hline \multicolumn{3}{|c|}{ Living conditions } \\
\hline Brick & $26 / 84(30.9 \%)$ & 0.050 \\
\hline Makeshift & $8 / 17(47.1 \%)$ & \\
\hline Homeless & $2 / 7(28.6 \%)$ & \\
\hline Wooden & $1 / 2(50.0 \%)$ & \\
\hline \multicolumn{3}{|c|}{ People per residence } \\
\hline $1-20$ & $10 / 33(30.3 \%)$ & 0.802 \\
\hline $21-50$ & $6 / 18(33.3 \%)$ & \\
\hline $51-100$ & $4 / 16(25.0 \%)$ & \\
\hline $101-500$ & $5 / 37(13.5 \%)$ & \\
\hline $501-1000$ & $2 / 6(33.3 \%)$ & \\
\hline \multicolumn{3}{|l|}{ Cooking } \\
\hline Yes & $18 / 46(39.1 \%)$ & 0.303 \\
\hline No & $9 / 64(14.1 \%)$ & \\
\hline \multicolumn{3}{|c|}{ Monthly expenditure (R) } \\
\hline$<100$ & $6 / 21(28.6 \%)$ & 0.037 \\
\hline $100-300$ & $4 / 37(10.8 \%)$ & \\
\hline$>300-500$ & $9 / 26(34.6 \%)$ & \\
\hline$>500-1000$ & $8 / 20(40.0 \%)$ & \\
\hline$>1000$ & $0 / 6(0 \%)$ & \\
\hline
\end{tabular}

\section{Discussion}

We found evidence of a deficiency in the health of the present immigrant population in Limpopo province. Information on the overall prevalence of diarrhoea in South Africa is lacking, so there is no figure with which to compare the prevalence found in this study. The mean number of diarrhoea episodes was calculated to be 0.38 per person in 2 weeks, which is much higher than the World Health Organization (WHO) estimate for sub-Saharan Africa of 1.29 episodes per person annually. ${ }^{7}$ This is probably because the WHO estimate is based on the entire population while this study focused on a vulnerable group.

Contrary to what one would expect, subjects with diarrhoea had more labour contract jobs and a higher monthly expenditure than those without diarrhoea. The fact that more of them lived in makeshift houses may have been the main factor contributing to the higher diarrhoea prevalence. Most immigrants generally rely on social welfare for food and accommodation, particularly immediately after entering the country and before getting a job. Once employed, immigrants are expected to move out of the shelter and fend for themselves. Most then move into makeshift houses and spend frugally. This dependence on public social infrastructure support may be dangerous for immigrants in the welfare system. The conditions in the available NGO shelters are generally poor owing to pressure on resources. No data were found in the literature to confirm these findings. The variables identified in this study provided an association, not a causal relationship, which would require a cohort study. Further studies are needed to address the relationship between risk factors and diarrhoea in greater depth.

A surveillance system could provide a way to recognise diarrhoea outbreaks early and prevent further spread. Continuous prevention efforts should include public awareness and educational campaigns on sanitation, hygiene and water quality and methods of household treatment and water and food storage.

\section{References}

1. Rutherford B. Zimbabweans living in the South African Border-Zone: Negotiating, suffering and surviving. Concerned Africa Scholars 2008;80:36-42.

2. Chirwa A, Finger A, Polzer T, Misago J, Schroeder J, Vigneswaran VD, eds. Fact or fiction? Examining Zimbabwean Cross-border Migration into South Africa: Special Report for the Forced Migration Studies Programme and Musina Legal Advice Office. Johannesburg: University of the Witwatersrand, 2007: 1-13.

3. ACT Alert No. 1/07: Vulnerable Zimbabweans in South Africa., Switzerland: Action by

ACT Alert No. 1/07: Vulnerable Zimbabweans in South Africa., Switzerland: Action Churches Together, 2007. http://www.reliefweb.int/rw/RWB.NSF/db900SI

4. Daily cholera updates and alerts. Cholera Country Profile: Zimbabwe. Geneva: World Health Organization, 2009: http://www.who.org/ (accessed 27 February 2010)

5. WHO Cholera Fact Sheet 2. Geneva: World Health Organization, 2007. http://www.who.org/ (accessed 20 February 2010)

6. National Institute for Communicable Diseases. Cholera outbreak in South Africa: Preliminary descriptive epidemiology on laboratory-confirmed cases, 15 November 2008 to 30 April 2009. Communicable Diseases Surveillance Bulletin 2009;7(2):1. http://www.nicd.ac.za/pubs/survbull/ surv_bull_may09.htm\#head2 (accessed 13 January 2011)

7. Hutton G, Haller L. Evaluation of the Costs and Benefits of Water and Sanitation Improvements at the Global Level. Water Sanitation and Health Protection of the Human Environment. Geneva: World Health Organization, 2004

Accepted 14 January 2011. 